Психология. Журнал Высшей школы экономики,

2019. T. 16. № 3. C. 457-469. DOI: 10.17323/1813-8918-2019-3-457-469

\title{
ОПЫТ ГУМАНИТАРНОГО ИССЛЕДОВАНИЯ ЛИЧНОСТИ МАРИНЫ ЦВЕТАЕВОЙ
}

\author{
В.М. РОЗИН
}

${ }^{a}$ Федеральное государственное бюджетное учреждение науки Институт философии Российской академии наук, 109240, Россия, Москва, ул. Гончарная, д. 12, стр. 1

\begin{abstract}
Резюме
В статье предлагается реконструкция личности Марины Цветаевой в рамках гуманитарнопсихологического исследования. Автор рассматривает принцип такого анализа, в частности, как позволяющий уточнить, с одной стороны, общие, неспецифические характеристики гуманитарной науки, с другой - специфические, отличающие ее, например, от естественных наук. В авторской версии Марина Цветаева предстает достаточно необычно: она эгоист, эзотерическая личность на почве поэзии, что позволяет ей не стоять на стороне нравственности и общественной морали, кроме того, Цветаева - множественная личность. Разбирая особенности двух личностей Цветаевой, автор опирается и на интересные психологические исследования субличности Р. Шварца и неадаптивной личности В.А. Петровского. Все это позволяет автору объяснить странные поступки Цветаевой, роль ее дневников, даже трагедию, которая с ней произошла. При этом автор показывает, что гуманитарная наука, с одной стороны, представляет собой настоящую науку, поскольку в ней решаются определенные проблемы, реальность познается путем конструирования идеальных объектов, гуманитарные исследования разворачиваются в рамках науки как одного из институтов современной культуры (модерна). С другой стороны, гуманитарная наука имеет ряд специфических особенностей: опора на тексты, включение в идеальные объекты характеристик, описывающих взаимоотношения исследователя с исследуемым субъектом, особые критерии истинности и объективности гуманитарных знаний. С точки зрения автора, методология гуманитарнопсихологического исследования, предполагающая анализ выделенной ситуации и проблем, приписывание изучаемой личности фиксированных характеристик, позволяющих эти проблемы разрешить, предоставление личности «голоса», (по М. Бахтину), позволяет сделать психологическое осмысление личности более основательным и обоснованным.
\end{abstract}

Ключевые слова: наука, исследование, интерпретация, текст, объект, истина, произведение, реальность, реконструкция, критика, проблема.

В психологии, как известно, существуют две разные традиции понимания методологии научного исследования. Согласно первой, в качестве идеала науки рассматривается естествознание, согласно второй - гуманитарная наука. Анализу сущности и характеристике гуманитарной науки и гуманитарным исследованиям я посвятил две книги и несколько статей (Розин, 2008, 2009). Тем не менее хочу еще раз рассмотреть эти темы на материале «множественной личности», точнее, ее психологической и гуманитарной реконструкции. 
В качестве объекта психолого-гуманитарного исследования я выбрал не совсем обычную личность - Марины Цветаевой, знаменитого и многими любимого поэта. Начиная обсуждение заявленной темы, очевидно, я должен пояснить, как понимаю, что такое личность, гуманитарное исследование и гуманитарная наука.

Во-первых, я не думаю, что личность всегда присутствует в человеке, до поры до времени она находится в анабиозе, просыпаясь тогда, когда человек сталкивается с противоречиями. Так, например, считает Александр Асмолов. «Итак,- пишет он,- на самых разных этапах человеческой истории в развитии культуры ведут между собой нескончаемый диалог социотипическое и индивидуальное поведение личности. Наличие этого диалога служит доказательством того, что в истории не было безличного периода существования общества. <..> Поиск “двигателя”, дающего начало активности личности, необходимо искать в тех рождающихся в процессе потока деятельностей противоречиях, которые и являются движущей силой развития личности. <...> Выступая как источник развития личности, социально-исторический образ жизни как бы задает появившемуся на свет человеку сценарий, втягивая его в определенный распорядок действий. Жесткость этого распорядка действий зависит прежде всего от того, насколько варьирует в конкретном социальноисторическом образе жизни свобода выбора тех или иных видов деятельности» (Асмолов, 2001, с. 195, 310, 340).

Исследования показывают, что личность - культурно-историческое образование, в филогенезе она впервые складывается в античной культуре, а затем проходит длинный путь развития, приобретая определенные черты только в культуре Нового времени; если же говорить об онтогенезе, то личность начинает формироваться в подростковый период (Розин, 2012a). При этом мое понимание личности близко концепции В.С. Библера, который на материале Средних веков характеризует личность таким образом: «Сопряжение Простеца и Схоласта (с включением Мастера как медиатора этих полюсов) есть решающее - для идеи личности - несовпадение индивида с самом собой в контексте средневековой культуры. - То несовпадение и та возможность самоотстранения и самоостранения, что позволяет индивиду этой эпохи вырываться за пределы внешней социальной и идеологической детерминации и самодетерминировать свою судьбу, свое сознание, т.е. жить в горизонте личности. То есть быть индивидом, а не социальной ролью. Здесь необходимое взаимоопределение между регулятивной идеей личности (в реальной жизни средневековой, античной или нововременной - личность всегда только регулятивна и никогда не налична) и актуальным бытием индивида. Нет индивида вне идеи личности; нет личностного горизонта вне самообособления индивида (вне одиночества)» (Библер, 1990, с. 122). По моему мнению, две основные характеристики личности являются самыми важными: первая личность действует самостоятельно (без чего невозможны поступок и выбор и что предполагает определенное несовпадение, а иногда и противопоставление индивида и общества), вторая - личность выстраивает под себя мир и себя в нем (здесь можно говорить о «Я-концепции», «скрипте», «жизненном 
сценарии») (Розин, 2009, 2012а). Говоря «выстраивает», я имею в виду деятельностное и семиотическое истолкование, но с точки зрения самой личности, конечно, лучше использовать другие выражения: например, индивид осознает наличие (или появление) определенных состояний своей психики (сознания).

Теперь о понимании гуманитарного исследования и науки. Известно, что гуманитарная наука сложилась только в XX столетии, в эпоху модерна, и как наука модерна несет на себе родовые черты своего времени. Так, исследователи-гуманитарии стремятся в своих работах к объективности, ориентируются на практическое приложение своих знаний, стараются мыслить строго (научно), зависят от поддержки государства и пользователей гуманитарных знаний. Но понять одновременно особенности гуманитарного подхода и мышления невозможно, не анализируя, как формировались идеалы гуманитарной науки (известно, что они складывались в оппозиции естественной науке), какие проблемы и задачи решает эта наука, каковы особенности построения в гуманитарной науке идеальных объектов и теоретического дискурса, чем вообще гуманитарная наука отличается от других наук и философии.

На мой взгляд, современная наука - не только новоевропейский феномен, но и результат развития науки, начиная с Античности. Например, вошедшие в концепцию науки установки на построение идеальных объектов, непротиворечивого знания, построение теории, решение проблем, объяснение эмпирических фактов сложились именно в античной «второй философии» (Аристотель), которая в эллинистический период обособилась как наука (Розин, 2018а).

Существенно различаются дискурсы естественной и гуманитарной науки (Розин, 2009). Прежде всего, в гуманитарной науке изучаются не природные явления и процессы, а тексты и производящие их индивиды, а также культура. Причем изучаются рефлексивно, так что может даже возникнуть вопрос «Наука ли это?». «Если понимать текст широко,- пишет М.М. Бахтин, - как всякий связанный знаковый комплекс, то искусствоведение имеет дело с текстами. Мысли о мыслях, переживания переживаний, слова о словах, тексты о текстах. В этом основное отличие наших (гуманитарных) дисциплин от естественных (о природе)... Науки о духе. Дух не может быть дан как вещь (прямой объект естественной науки), а только в знаковом выражении, реализации в текстах... Каждый текст (как высказывание) является чем-то индивидуальным, единственным и неповторимым, и в этом весь смысл его... он (в своем свободном ядре) не допускает ни каузального объяснения, ни научного предвидения... Возникает вопрос, может ли наука иметь дело с такими абсолютно неповторимыми индивидуальностями... не выходят ли они за рамки обобщающего научного познания. Конечно, может» (Бахтин, 1979, с. 281, 283, 285, 287).

Как правило, начинается гуманитарное исследование с констатации экзистенциальной ситуации, в которую попадает исследователь и которая его затрагивает и требует разрешения. Например, исследование личности А.С. Пушкина автор начал потому, что прочел письма поэта и работы пушкиноведов, которые 
разрушали сложившийся у него, нужно признаться, идеальный образ Александра Сергеевича (Розин, 2009, с. 109-110, 115).

Гуманитарное исследование обязательно предполагает построение идеальных объектов, т.е. приписывание изучаемой личности (культуре) фиксированных характеристик, которые должны обеспечивать непротиворечивость гуманитарного дискурса, возможность решения стоящих перед гуманитарием проблем, объяснять факты, в данном случае истолкование текстов и стоящей за ними личности (Розин, 2008, с. 84, 2018б, с. 59-61). Однако М.М. Бахтин писал, что в гуманитарной науке личности «нельзя созерцать, анализировать, определять как объекты, как вещи, - с ними можно только диалогически общаться. Думать о них - значит говорить с ними, иначе они тотчас же поворачиваются к нам своей объектной стороной: они замолкают, закрываются и застывают в завершенные объектные образы» (Бахтин, 1979, с. 116). Конструирование идеальных объектов в гуманитарном исследовании должно удовлетворять требованию - предоставить голос изучаемой личности, т.е., приписывая этой личности характеристики, исследователь должен позволять ей высказываться (ну конечно, не прямо, а посредством текстов или правдоподобных имитаций подобных текстов самим исследователем).

Наконец, гуманитарное исследование адресуется определенной гуманитарной аудитории, и часто исследователь хочет ей что-то сказать вполне конкретное. Охарактеризую теперь непосредственно экзистенциальную ситуацию, которая меня задела и потребовала обсуждения. При этом я буду опираться на реконструкцию личности Марины Цветаевой, изложенную в статье «Личность и трагедия Марины Цветаевой» (Розин, 2012б).

Историю, о которой пойдет речь, рассказала на своем сайте цветаевед Анна Кирьянова. «В голодные годы, - пишет она, - Марина сдала в Кунцевский приют своих дочерей. Кормить детей ей было тяжело: со службы она ушла, так как ей было скучно, неинтересно, бессмысленно переписывать глупые бумаги... <..> Детей она сдала в приют, написав заявление, что это - чужие дети, которых она нашла под дверью. Иначе при живой матери девочек в приют бы не взяли. Может быть, спасли бы им жизнь. В приюте старшая, Аля, тяжело заболела, а младшая, Ирина, умерла с голоду. “Впрочем, так лучше”, - писали друг другу знакомые, хорошо знавшие Марину. Ведь ребенок не видел ничего, кроме побоев и голода. Марина уходила на поэтические посиделки, привязав двухлетнюю Ирину за ногу к кровати в темной комнате. Под кроватью жили крысы. <..> Привязывать ребенка Марина стала после того, как девочка наелась всякой гадости из помойного ведра. <..> На похороны дочери Марина не пошла» (Кирьянова, 2006).

Моя супруга, указала мне на сайт, где эта не укладывающаяся в голове история широко обсуждается. Высказывания участников дискуссии можно свести к трем точкам зрения. Одна точка зрения: Цветаева была эгоисткой, ее интересовала только собственная поэзия; как следствие смерть Ирины и искалеченная жизнь Али. Вторая точка зрения: Марина Ивановна была больным человеком, не совсем психически здоровым. И третья точка зрения: страшное время, великий поэт, гении нам неподсудны. 
Какие конкретно проблемы стояли передо мною? Во-первых, я хотел понять поведение Цветаевой; для меня так же, как и для участников обсуждения в Интернете, поведение великой поэтессы представляло личную экзистенциальную проблему, поскольку вслед за самой Цветаевой, написавшей эссе «Мой Пушкин», я мог бы сказать «Моя Цветаева». Во-вторых, я хотел получить материал для методологического анализа особенностей гуманитарной науки, в том числе психологии. Обе эти задачи можно было решить, построив сначала идеальный объект, приписав Цветаевой фиксированные характеристики. На их основе можно было уже развернуть гуманитарный дискурс, отвечающий на оба поставленных вопроса. Вот фиксированные характеристики, которые я приписал Цветаевой.

Как ни понимать эгоизм, все-таки Цветаеву можно отнести к этой категории. Например, сдавая дочерей в приют, она пишет любимой Ариадне: «Милая Алечка, не томись, не горюй. То, что сейчас бессмысленно, окажется мудрым и нужным, только надо, чтобы время прошло! - Нет ничего случайного!». В это время Аля в приюте пишет такое письмо: «Мама! Я повешусь, если Вы не приедете ко мне, или мне Лидия Александровна не даст весть об Bac! Вы меня любите? Господи, как я несчастна! Из тихой тоски я перехожу в желание отомстить тому, кто это сделал. О я Вас прошу, любите, пожалуйста, меня, или я умру самой мучительной смертью». Но Цветаева не приезжает и никаких известий Але не передает, зато сочиняет красивые и печальные стихи о своей разлуке с дочерью (Эфрон, 2009). Первая характеристика личности Цветаевой - она эгоист.

Вторую характеристику своей личности Цветаева фактически сформулировала сама: она - великий поэт, поэзия для нее - главная реальность, позволяющая жить вне нравственности и оправдывать любые поступки. «Художественное творчество, - пишет Цветаева в статье «Искусство при свете совести», - в иных случаях некая атрофия совести, больше скажу: необходимая атрофия совести, тот нравственный изъян, без которого ему, искусству, не быть. Чтобы быть хорошим (не вводить в соблазн малых сих), искусству пришлось бы отказаться от доброй половины всего себя. Единственный способ искусству быть заведомо хорошим - не быть. Оно кончится с жизнью планеты. <..> “Исключение в пользу гения”. Все наше отношение к искусству - исключение в пользу гения. Само искусство тот гений, в пользу которого мы исключаемся (выключаемся) из нравственного закона. $<$...> Состояние творчества есть состояние сновидения, когда ты вдруг, повинуясь неизвестной необходимости, поджигаешь дом или сталкиваешь с горы приятеля. Твой ли это поступок? Явно - твой (спишь, спишь ведь ты!). Твой - на полной свободе, поступок тебя без совести, тебя - природы. <...> Часто сравнивают поэта с ребенком по примете одной невинности. Я бы сравнила их по примете одной безответственности. Безответственность во всем, кроме игры» (Цветаева, 1997).

Наконец, вывод, подтверждающий, что поэзия для Цветаевой была главной реальностью. «Посему, если хочешь служить Богу или людям, вообще хочешь служить, делать дело добра, поступай в Армию Спасения или еще 
куда-нибудь - и брось стихи. <..> И зная это, в полном разуме и твердой памяти расписавшись в этом, в не менее полном и не менее твердой утверждаю, что ни на какое другое дело своего не променяла бы. Зная большее, творю меньшее. Посему мне прощенья нет. Только с таких, как я, на Страшном суде совести и спросится. Но если есть Страшный суд слова - на нем я чиста» (Там же).

Третья характеристика личности Цветаевой, кстати, доказывающая, что она была психически здорова, - Марина была умным человеком, хорошо осознающим, что она делает. Об этом свидетельствует ее дневник. Вот фрагмент из него.

«Ирина! - Я теперь мало думаю о ней, я никогда не любила ее в настоящем, всегда в мечте - любила я ее, когда приезжала к Лиле и видела ее толстой и здоровой, любила ее этой осенью, когда Надя (няня) привезла ее из деревни, любовалась ее чудесными волосами. Но острота новизны проходила, любовь остывала, меня раздражала ее тупость (голова точно пробкой заткнута!), ее грязь, ее жадность, я как-то не верила, что она вырастет - хотя совсем не думала о ее смерти - просто, это было существо без будущего... Иринина смерть для меня так же ирреальна, как ее жизнь. - Не знаю болезни, не видела ее больной, не присутствовала при ее смерти, не видела ее мертвой, не знаю, где ее могила.

- Чудовищно? - Да, со стороны. Но Бог, Видящий мое сердце, знает, что я не от равнодушия не поехала тогда в приют проститься с ней, а от того, что НЕ МОГЛА. (К живой не приехала...)

Ирина! Если есть небо, ты на небе, пойми и прости меня, бывшую тебе дурной матерью, не сумевшую перебороть неприязнь к твоей темной непонятной сущности» (Цветаева, 2002).

Теперь не менее важная характеристика личности Цветаевой: она была «множественной личностью», в Цветаевой жили два разных человека, которые попеременно овладевали ее душой и сознанием, реализуя, как правило, прямо противоположные и несовместимые формы поведения и поступки (Розин, 2015). Первая личность - это личность, условно говоря, «поэта-эзотерика», склонного считать поэтическую реальность главной и подлинной, а обычный мир второстепенным. Личность, реализующая себя в поэтическом творчестве, а также в формах романической жизни, где измены - не измены, а необходимый для гения опыт, люди - не люди, а почитатели твоего таланта и средства твоей жизни, жизненные обстоятельства - не обстоятельства, если они противоречат поэтической реальности. Для художника несложно переинтерпретировать любое обычное обстоятельство, в том числе и свои поступки, как подтверждающие или противоречащие подлинной реальности, подобно тому как Цветаева все события истолковывала в том плане, который ей был нужен для продолжения своего творчества.

Вторая личность - обычная, непоэтическая, отчасти даже нравственная, но только отчасти. В силу воспитания, влияния матери, времени Цветаева при всем ее уме и знаниях была очень маргинальна, жила, как бы сказал Михаил Бахтин, идеями («человек идеи»), а я бы сказал, что она во многом жила 
абстрактными схемами. Отсюда абсолютная непрактичность, нежелание и неумение понять других, метания и странные поступки. Все это, конечно, было усугублено и тотальным влиянием первой личности. Дело в том, что обе личности Цветаевой не были разделены «китайской стеной», напротив, первая все время навязывала второй неадекватное с точки зрения социальной логики и здравого смысла поведение. И в истории с дочерями она сыграла свою роковую роль. Сначала под ее влиянием Марина пришла к выводу, что детям в приюте будет лучше, потом, что забирать их еще рано, что Ирина дефектная и поэтому недостойна заботы.

Описывая «личности Цветаевой», я понимаю, что это всего лишь гипотеза и что еще большой вопрос, являются ли ипостаси множественной личности личностями. Например, в книге «Феномен множественной личности» я показываю, что личности ее главного героя Билли Миллигана не являются собственно личностями, что это обособивииеся режимь психики, которые, однако, воспринимаются сознанием Билли как самостоятельные субъекты (Розин, 2015, с. 171-172). Думаю, что и «субличности» Ричарда К. Шварца нельзя подвести под понятие «личность», и не случайно Шварц называет их «персонажами», хотя и говорит о «внутренней семье» отдельного индивида (Шварц, 2011; Русак, 2017).

И смысловые миры, по теории В.А. Петровского, соприсутствующие в личности, не являются настоящими личностями, хотя тоже, возможно, могут иногда восприниматься личностью как самостоятельные субъекты. Но вот его концепция «надситуативной активности» вполне подходит для осмысления личности Цветаевой. Она действительно в дневниках как бы встает над своими двумя «личностями». Если следовать представлению Петровского, что в единстве всех ипостасей определяется Я и его свобода (Петровский, 2010, c. 200), то можно предположить, что Цветаева периодически пытается восстановить свое Я как целое.

Опираясь на указанные характеристики личности Цветаевой, можно предложить следующее объяснение ее поступков. Во-первых, становится понятной роль ее дневников. Это не маниакальное графоманство, представляющее собой канал реализации плохой энергии (так утверждал один из участников обсуждения в Интернете), а способ связи двух персон Цветаевой. Второй персоне (личности) необходимо было на что-то опираться, когда она не знала, как действовать в критических ситуациях. На саму себя она опираться не могла, ведь за ней стояла первая персона. В этих условиях Цветаева открыла, что дневник является инструментом осмысления воли ее первой персоны. Например, описывая посещение приюта, она фактически занимается оправданием желаний и поступков первой персоны. При этом рассказывает и о поступках в обычной реальности (игнорирует Ирину, не забирает из приюта детей). Заметим, решение второй персоны идет навстречу желаниям первой.

Доминирование первой персоны объясняет и такой странный факт, что, описывая посещение приюта, Цветаева не замечает чудовищности своего поведения. Здесь, на мой взгляд, вступает в свои права «символическая амнезия»: человек вроде бы осознает и помнит свои действия, но не относит их к 
себе (как будто они совершаются кем-то другим). Получается, что без непрерывного описания своей жизни и поступков в дневнике Цветаева не могла жить. Вероятно, если бы она перестала вести дневник, обе ее персоны не смогли бы существовать, что уже грозило прямым психическим нарушением. Возможно, оно и случилось, когда Цветаева вернулась в СССР и не смогла ни писать стихи, ни выступать перед публикой. Мстя за неправильный выбор, лишающий возможности творить, первая персона толкает вторую на самоубийство, считая ее ответственной за решение вернуться на родину. Но в данном случае самоубийство касалось и первой персоны.

Во-вторых, мы начинаем понимать, что поступок Цветаевой не был каким-то случайным отклонением, он вполне закономерен. В-третьих, выявленные особенности личности Цветаевой позволили понять, почему я относительно холоден к ее поэзии. С одной стороны, я всегда признавал достоинство ее художественного творчества: для ее стихов характерны яркая образность, эмоциональность, страстность, необычная форма, точность выражения, своеобразная художественная мысль. С другой стороны, поэзия Цветаевой меня никогда не трогала, не заставляла сопереживать, оставляла холодным. Не потому ли, что Цветаева всегда пишет только о себе, а о других только мимоходом. Не потому ли, что Марине не были близки переживания других людей, что она никогда с ними не отождествлялась, в каком-то смысле не сочувствовала никому. Ей, вероятно, была незнакома общая жизнь с другими («возлюби ближнего как самого себя»), предполагающая совместные переживания, горе, радость, сочувствие. Например, Аля в приюте умоляет мать приехать, а Цветаева не приезжает, но пишет такие стихи.

Маленький домашний дух,

Мой домашний гений!

Вот она, разлука двух

Сродных вдохновений!

Жалко мне, когда в печи

Жар, - а тьл не видишь!

В дверь - звезда в моей ночи!

Не взойдешь, не выйдешь!

Платьица твои висят,

Точно плод запретныц.

На окне чердачном - сад

Расцветает - тщетно.

Голуби в окно стучат, -

Скучно с голубями!

Мне ветра привет кричат, -

Бог с ними, с ветрами!

Не сказать ветрам седьм,

Стаям голубиным -

Чудодейственным твоим

Голосом: - Марина! 
Теперь, как данное гуманитарное исследование выглядит в плане требований модерна, ведь, как я отмечал, современная наука не только ассимилировала представления, сложившиеся в античной и средневековой культуре и эпохе Возрождения, но и является социальным институтом новоевропейской культуры. Как социальный институт наука выполняет в культуре сощиальную миссию, ориентирована на практические приложения, описывает объективную реальность, поддерживается государством и обществом, предполагает подготовку специалистов-ученых.

Не исключение и данное исследование. У него была ясная, двойная практическая ориентация: во-первых, я хотел понять, как следует относиться к личности Марины Цветаевой, во-вторых, на материале данного исследования я рассчитывал выявить особенности гуманитарной науки и исследования. Социальная миссия проведенного исследования - расширение возможностей свободы (эту роль, правда, относительно социальной науки в работе «Мыслить социологически» отмечал 3. Бауман; но и гуманитарная наука, на мой взгляд, должна идти в том же русле). Свобода в данном случае может быть понята, например, по Бахтину, скажем, как требование предоставить голос изучаемой личности. Я старался предоставить голос самой Цветаевой, цитируя ее дневники или статью «Искусство при свете совести».

Теперь вопрос относительно объективности полученных в исследовании результатов, но объективность, естественно, должна быть понята в гуманитарном ключе. Я не отрицаю, что создавал версию (реконструкцию) личности Цветаевой. Одновременно допускаю, что существуют другие версии этой личности или что могут быть созданы новые, не хуже моей. Во-первых, я постарался понять Цветаеву даже по отношению к ее нелюбимой дочери Ирине, во-вторых, не могу ее оправдать (понять не означает оправдать), в-третьих, никогда бы не бросил в нее камень (кто не без греха!), в-четвертых, считаю, что если нас самих в нас что-то не устраивает, то нужно это признать и начать работать над собой, чтобы стать лучше (другое дело, что из этого получится).

В точном соответствии с пониманием научной объективности и строгости я опирался на тексты, которые при правильной интерпретации выступают для гуманитарной науки в качестве фактов. Фиксировал и анализировал версии других исследователей Цветаевой, а также ее читателей в Интернете. Старался мыслить логически правильно и правдоподобно в плане построения интерпретаций ее личности и даже взглянуть на свою версию критически с точки зрения других подходов (в этом отношении гуманитарный дискурс, как отмечают некоторые исследователи, сближается с юридическим).

В плане критерия гуманитарной и психологической истины я исхожу из убеждения, что моя версия событий и личности Цветаевой интересна вовсе не для всех, а только для определенной аудитории, представители которой разделяют мои ценности и методологические установки. Для остальных она может быть ложной или произвольной в тех или иных отношениях.

Если объективность естественно-научных исследований удостоверяется в инженерии и технике (скажем, самолеты, построенные с использованием законов природы, летают, а не падают), то гуманитарную и психологическую 
объективность данного исследования автор удостоверяет в собственной личной практике. Так, я не знал, как понять поступок Цветаевой и каким образом с этим дальше жить (общаться, сочувствовать или нет, задавать ей вопросы и ждать откликов в виде стихов или исповедей в дневнике и пр.), но после исследования ее личности смог самоопределиться. Теперь я лучше понимаю ее поэзию и поступки (не только проанализированный, но и другие), не могу оправдать ее отношение к детям, но получил важный материал для уточнения своей концепции гуманитарной науки.

Еще один момент. Исследования личности Цветаевой я излагал в форме докладов в разных аудиториях и опубликовал в научной печати. А следовательно, я принимаю сложившиеся в современной науке «критерии научности» (объективности, строгости, доказательности, общезначимости и др.). Одновременно я уточняю эти критерии или даже пересматриваю их применительно к особенностям гуманитарного подхода и науки. Но во всех случаях стараюсь познакомить научную общественность с результатами своих исследований и размышлений, чтобы они стали достояниям науки и философии.

В целом проведенное исследование личности Марины Цветаевой вместе с другими гуманитарными исследованиями автора позволяют убедиться в том, что гуманитарная наука является настоящей наукой, а не вариантом нестрогого образного мышления, как утверждают психологи, ориентированные на идеал естествознания. В ней решаются определенные проблемы, действительность познается путем конструирования идеальных объектов, гуманитарное исследование удовлетворяет требованиям науки как одного из институтов модерна. Кроме того, мы получаем подтверждение того, что гуманитарная наука обладает рядом специфических особенностей. Здесь проблемы - это проблемы самого исследователя и аудитории, разделяющей его ценности, ставятся с опорой на интерпретации текстов, идеальные объекты включают в себя характеристики взаимоотношений исследователя с исследуемым объектом (субъектом, личностью). Проблемы часто (но не всегда) получают свое разрешение в ходе гуманитарного исследования, т.е. в гуманитарной науке познание и решение практических задач иногда идут параллельно, они не разделены, как, например, в случае естественной науки и инженерии.

\section{Литература}

Асмолов, А. Г. (2001). Психология личности. Принципы общепсихологического анализа. М.: Смысл. Бахтин, М.М. (1979). Эстетика словесного творчества. М.: Художественная литература.

Библер, В. С. (1990). Образ Простеца и идея личности в культуре Средних веков. В кн. А.Я. Гуревич (ред.), Человек и культура (с. 81-125). М.: Наука. .

Кирьянова, А. (2006). Две души Марины Цветаевой. Режим доступа: https://www.proza.ru/2006/ 08/10-105

Петровский, В. А. (2010). Человек над ситуачией. М.: Смысл.

Розин, В. М. (2008). Наука: происхождение, развитие, типология, новая концептуализация. М./Воронеж: МПСИ/НПО «МОДЭК». 
Розин, В. М. (2009). Особенности дискурса и образцы исследования в гуманитарной науке. М.: ЛИБРОКОМ.

Розин, В. М (2012а). Личность и ее изучение (2-е изд.). М.: ЛИБРОКОМ.

Розин, В. М. (2012б). Личность и трагедия Марины Цветаевой. Культура и искусство, 5, 59-67.

Розин, В. М. (2015). Феномен множественной личности: По материалам книги Дэниела Киза «Множественные умы Билли Миллигана» (4-е изд.). М.: Ленанд.

Розин, В. М. (2018а). История и методология юридической науки. Юридическое мышление. Учебное пособие. 2-е изд. М.: Юрайт.Розин, В. М. (2018б). История и философия науки (2-е изд.). М.: Юрайт.

Русак, О. (2017). Системная терапия субличностей по Р. Швариу. Режим доступа: https://www.b17.ru/article/77871/

Цветаева, М. (1997). Искусство при свете совести. Режим доступа: http://brb.silverage.ru/zhslovo/sv $/$ tsv $/$ ?id= $=9 \& \mathrm{r}=$ proza

Цветаева, М. (2002). Из записных книжек и тетрадей. Режим доступа: http://modernlib.net/ books/cvetaeva_marina/iz_zapisnih_knizhek_i_tetradedy/read

Шварц, Р. К. (2011). Системная семейная терапия субличностей. М.: Научный мир.

Эфрон, И. (2009). Последние два месяца жизни. Режим доступа: https://wyradhe.livejournal.com/58265.html

Розин Вадим Маркович - главный научный сотрудник, Институт философии РАН, доктор философских наук, профессор.

Сфера научных интересов: методология, психология, философия.

Контакты: rozinvm@gmail.com

\title{
An Attempt of Humanitarian Research of Marina Tsvetaeva's Personality
}

\author{
V.M. Rozin ${ }^{\mathrm{a}}$ \\ ${ }^{a}$ Institute of Philosophy, Russian Academy of Sciences, $12 / 1$ Goncharnaya Str., Moscow, 109240, Russian \\ Federation
}

\begin{abstract}
The article proposes the reconstruction of the personality of Marina Tsvetaeva in the framework of humanitarian and psychological research. The author considers this analysis in particular as allowing to clarify, on the one hand, the general, non-specific characteristics of the humanities, on the other - specific, which distinguish it, for example, from the natural science. In the author's version, Marina Tsvetaeva looks rather unusual: she is an egoist, an esoteric personality based on poetry, which allows her to stand on the side of morality and public morality, finally, Tsvetaeva is a multiple personality. Analyzing the characteristics of Tsvetaeva's two personalities, the author also relies on interesting psychological studies on the subpersonalities of R. Schwartz and the non-adaptive personality of V. Petrovsky. All this allows the author to
\end{abstract}


explain Tsvetaeva's strange actions, the role of her diaries, even the tragedy that happened to her. At the same time, he shows that, on the one hand, the humanities science is a normal science, since it solves certain problems, reality is cognized by constructing ideal objects, humanitarian studies are developed within the framework of science as one of the modern institutions. On the other hand, the humanities have a number of specific features: reliance on texts, inclusion in ideal objects the characteristics, which describe the attitude of the researcher to the studied subject, special criteria of truth and objectivity in humanitarian knowledge. From the point of view of the author, the methodology of humanitarian-psychological research, which involves analyzing the situation and problems of the studied person, attributing to the person fixed characteristics that allow these problems to be resolved, giving the person the "voice", according to M. Bakhtin, makes psychological understanding of the person more substantive and reasonable.

Keywords: science, research, interpretation, text, object, truth, work, reality, reconstruction, criticism, problem.

\section{References}

Asmolov, A. G. (2001). Psikhologiya lichnosti. Printsipy obshchepsikhologicheskogo analiza [Psychology of Personality. Principles of general psychological analysis]. Moscow: Smysl. (in Russian)

Bakhtin, M.M. (1979). Estetika slovesnogo tvorchestva [Aesthetics of verbal creativity]. Moscow: Khudozhestvennaya literatura. (in Russian)

Bibler, V. S. (1990). Obraz Prostetsa i ideya lichnosti v kul'ture Srednikh vekov [The image of the prostate simpleton and the idea of personality in the culture of the Middle Ages]. In A. Ya. Gurevich (Ed.), Chelovek i kul'tura [Man and culture] (pp. 81-125). Moscow: Nauka. (in Russian)

Efron, I. (2009). Poslednie dva mesyatsa zhizni [Last two months of life]. Retrieved from https://wyradhe.livejournal.com/58265.html (in Russian)

Kiryanova, A. (2006). Dve dushi Mariny Cvetaevoj [Two souls of Maria Tsvetaeva]. Retrieved from https://www.proza.ru/2006/ 08/10-105 (in Russian)

Petrovsky, V. A. (2010). Chelovek nad situatsiei [Man over the situation]. Moscow: Smysl. (in Russian)

Rozin, V. M. (2008). Nauka: proiskhozhdenie, razvitie, tipologiya, novaya konceptualizaciya [Science: issues, development, typology, new conceptualization]. Moscow/Voronezh: MPSI/NPO «MODEK». (in Russian)

Rozin, V. M. (2009). Osobennosti diskursa i obraztsy issledovaniya v gumanitarnoi nauke [Features Specifics of discourse and samples of research in the humanities]. Moscow: LIBROKOM. (in Russian)

Rozin, V. M. (2012, a). Lichnost' i ee izuchenie [Personality and its study] (2nd ed.). Moscow: LIBROCOM. (in Russian)

Rozin, V. M. (2012, b). Lichnost' i tragediya Mariny Cvetaevoj [The personality and tragedy of Marina Tsvetaeva]. Kul'tura i Iskusstvo, 5, 59-67. (in Russian)

Rozin, V. M. (2015). Fenomen mnozhestvennoj lichnosti. Po materialam knigi "Mnozhestvennye umy Billi Milligana" [The phenomenon of multiple personality. According to Based on the book "Billy Milligan's Multiple Minds"]. Moscow: URSS. (in Russian)

Rozin, V. M. (2018, a). Istoriya i filosofiya nauki [History and philosophy of science] (2nd ed.). Moscow: Yurayt. (in Russian) 
Rozin, V. M. (2018, b). Istoriya i metodologiya yuridicheskoi nauki. Yuridicheskoe myshlenie [History and methodology of legal science. Legal thinking]. Moscow: Yurayt. (in Russian)

Rusak, O. (2017). Sistemnaya terapiya sublichnostei po R. Shvartsu [Systemic therapy of subpersonalities according to R. Schwarts]. Retrieved from https://www.b17.ru/article/77871/ (in Russian)

Schwarts, R. K. (2011). Sistemnaya semeinaya terapiya sublichnostei [Systemic family therapy]. Moscow: Nauchnyi Mir. (in Russian)

Tsvetaeva, M. (1997). Iskusstvo pri svete sovesti [Art in the light of conscience]. Retrieved from http://brb.silverage.ru/zhslovo/sv/tsv/?id=9\&r=proza (in Russian)

Tsvetaeva, M. (2002). Iz zapisnyh knizhek i tetradej [From notebooks pocket-books and notebooks]. Retrieved from http://modernlib.net/books/cvetaeva_marina/iz_zapisnih_knizhek_i_tetradedy/read (in Russian)

Vadim M. Rozin - chief research fellow, Institute of Philosophy, Russian Academy of Sciences, D.Sc., professor.

Research area: methodology, psychology, philosophy.

E-mail: rozinvm@gmail.com 